\title{
A TWO-DIMENSIONAL BASIS FOR THE INVESTIGATION OF ANGULAR CORRELATIONS IN HELIUM-LIKE SYSTEMS
}

\author{
M. I. Haysak ${ }^{\dagger}$, M. M. Dovhanich ${ }^{\dagger}$, V. I. Lengyel ${ }^{\dagger \dagger}$, V. V. Onysko ${ }^{\dagger \dagger}$ \\ ${ }^{\dagger}$ Institute of Electron Physics, 294016 Uzhgorod, Ukraine \\ ${ }^{\dagger \dagger}$ Uzhgorod State University, 294000 Uzhgorod, Ukraine
}

(Received September 6, 1996)

\begin{abstract}
By way of using the hyperspherical coordinates method a two-dimensional basis for the investigation of angular correlations in three-particle systems spectral characteristics is constructed. For two-electron systems like $\mathrm{He}$ and $\mathrm{H}^{-}$in adiabatic approximation the calculations of lower adiabatic potentials for one- and two- particle-states (autoionisation states) as well as of the angular part of their wave-functions are carried out. The crossing points of adiabatic potentials are revealed, which characterize the regions of nonadiabatic transitions between autoionising states. The classification of a series of quantum states on the basic of knot-lines of basis functions is also carried out.

Key words: angle correlations, two-dimensional basis, hyperspherical method, adiabatic potential, autoionisation states, sweep method, helium-like systems.
\end{abstract}

PACS number(s): 02.60.Lj, 02.70.Hm, 03.65.Ge, 31.10.+z, 31.20.Di, 31.20.Tg

\section{INTRODUCTION}

The notions of both one-particle aspects of electron motion in atoms based on a self-consistent method and the collective ones tracing back to the acoustical waves are equally widely used in different areas of physics for the description of few-body systems. These ideas allow one to reflect the main characteristics of the correlated motion. The effects due to such motion of particles are revealed in molecular and nuclear physics as well as in solid state physics. Though in atomic physics the vibrational motion analog is not discovered, in certain cases of excitation, ionization and even in elastic scattering of electrons on atomic systems the correlated motion is clearly established and the study of this motion of particles is one of the most hecticly discussed problems today.

A very interesting approach to the study of short-range and long-range correlations is developed by I. Vakarchuk and I. Yukhnovsky $[1,2]$. This approach allowed them to explain quantitatively a set of structural features of liquid helium $\mathrm{He}^{4}$. But in atomic [3-6] as well as in nuclear physics [7] the so-called method of hyperspherical coordinates (MHC) proved to be the most appropriate one for accounting the above-mentioned correlation. The way of developing this method was not straightforward. Different kinds of one-particle approaches were investigated for the definition of spectral characteristics of atomic systems. At the beginning the Hartree-Fock (HF) method seemed to be quite satisfactory [8]. The difference between the results, obtained by means of this method and the experimental data is exactly the measure of this correlation. Going outside the HF method renders it possible to account for the correlation. Several methods were elaborated for this aim. Among the most promising one seemed to be the multiconfigurational Hartree-Fock [9], configuration interactions (CI) [10, 11], strong-coupling or close-coupling method $[12,13]$. The basic idea of a method of a such type leads postulating some kind of a class of trial functions which together with its mathemat- ical basis constitutes the Galerkin-Ritz method [14]. The results obtained in these approaches generally speaking depend on the functions used as well as on the dimension of the basis used for diagonalizing the Hamiltonian of the system. Advent of powerful computing facilities allows one to consider the spaces precisely. This also allows one to obtain the energy with quite large precision. But the use of different ways of taking into account singularities of Shrödinger equation [15-19] leads to a noticeable difference in the integral characteristics of systems though the values of energy which practically do not change [1719]. In this respect the use of the collective coordinates offers quite new possibilities.

The investigations of the correlation in $\mathrm{MHC}$ at the small values of the hyperradius were carried out for the first time by J. Bartlet [15] and V. Fock [16] on the basis of studying the ground state of the helium atom. It was shown in these works that in the vicinity of a triplecollision point the expansion of the wave-function contains not only power-law type terms, but also it contains the logarithmic terms. Accounting for this fact helped to accelerate the convergence of variational calculations [20].

Several works were devoted to the study of correlations in atomic systems at medium and asymptotic values of hyperradius (see, e.g. the reviews [4-6]). Accounting for the correlations at medium values of hyperradius is important for obtaining the parameters of autoionising states (AIS).

In the works of Macek, Lin, Fano [3-5] a very important feature of hyperspherical coordinates was established. Namely it turned out that the approximate separation of variables is possible for the wave function. It allows one to consider one single term in the expansion of the wave-function in terms of the so-called channel functions. The approximate adiabatic expansion means that one can separate the variables into rapidly changing (angular) variables and slowly changing (connected with hyperradius). Such a picture is totally analogous to the 
situation in molecular physics, where the rapid motion is connected with electrons, while the slow one is connected with the nuclei. This fact allows one to suggest the existence of collective motions in atom, the nature of which is not established yet.

Let us remind the reader that in molecular physics one has the clear parameter which secures the adiabatic conjecture, namely the ratio of the electron mass to the nuclear mass. In the atomic physics such a parameter is absent and only the numerical calculation can prove its validity. The same situation is inherent to Hartree-Fock method [8] where such a parameter as smallness which secures its application is also absent. Nevertheless this method is an excellent model of one-particle approximation in many-particle theory.

At the moment the adiabatic separation of variables in $\mathrm{MHC}$ has become a powerful method of investigation of two-electron systems both in the energy spectrum sector of calculations and in the scattering sector [3-6, 2124]. Moreover this method is generalized for the outer shell [25, 26]. The MHC allows one also to carry out the natural and visual classification of quantum states of the system. The states of the system are described by the quantum number of level $(n)$ in adiabatic potential, which, in turn, is characterized by the index $(\mu)$ renumerating these potentials. This index (actually it is a set of indices) appears as a result of quantization in respect to angular variables. Therefore the larger is the number of angular variables the more complicated the nature of this index is.

Studying the vibrational-rotational spectra of twoelectron systems and basing on group properties of interacting electrons Herrick [28] suggested using two quantum numbers $(\mathrm{K}, \mathrm{T})$ which are connected with the eigenvalues of Kazimir operators of $O\left(4_{1}\right) \times O\left(4_{2}\right)$ group and are characterizing the multiplet of states. Later Lin [5] used these quantum numbers for the classification of twoelectron states in $\mathrm{MHC}$.

Lin has shown that for the definition of $\mu$ it is necessary to introduce one additional empiric quantum number $A$, which characterizes the behaviour of the channel function in the vicinity of an $\alpha=\pi / 2$ point and to which three values are ascribed, namely $+, 0,-$. Actually this means, that the type of the correlation is defined by the type of charge density [29], which remains unchanged in a wide interval of hyperradius values. The classification, proposed by Lin [5] has a semiempirical character, since it is not connected with the singling out in the Hamiltonian of the corresponding dynamical variables. Therefore the problem of finding a more natural classification of the two-electron system remains timely at the moment.

For expanding the region of application of $\mathrm{MHC}$ we propose to use as a basis the two-dimensional channel functions. The solution of this problem can be realized by using sweep method with conditions of conjugation $[30,31]$. This method was successfully applied for the definition of eigen frequencies of the vibrations of a rect- angular plate of varying thickness and a stiffened plate. Such an approach allows one to formulate boundary conditions put on the angular part of wave-functions and to carry out a more complete account of angular and radial correlations. In this work we propose also to carry out the classification of adiabatic potentials of two-electron systems by means of using characterizing nodal lines of two-dimensional eigenfunctions of boundary problem. It will be shown that for the unambiguous definitions of $\mu$ it is necessary to introduce two numbers which are connected with the quantization of a two-dimensional boundary problem.

\section{THE EQUATION FOR A TWO-DIMENSIONAL BASIS OF HELIUM-LIKE SYSTEMS}

The description of the dynamics of a two-electron system is reduced to the solution of the non-relativistic stationary Shrödinger equation which has the form (in the atomic units) of

$$
\begin{aligned}
& {\left[-\frac{1}{2} \Delta_{1}-\frac{1}{2} \Delta_{2}+\frac{Z}{r_{1}}+\frac{Z}{r_{2}}-\frac{1}{\left|\overrightarrow{r_{1}}-\overrightarrow{r_{2}}\right|}\right]} \\
& \times \Psi\left(\overrightarrow{r_{1}}, \overrightarrow{r_{2}}\right)=E \Psi\left(\overrightarrow{r_{1}}, \overrightarrow{r_{2}}\right),
\end{aligned}
$$

where $\Delta_{i}$ is Laplass's operator acting on the radiusvector $\vec{r}_{i}, Z$ is a charge of the nucleus, $E$ is the energy of relative motion of electrons. For defining the partial solutions of eq. (1) it is convenient to pass to the rotating system of coordinates.

Let us choose the following independent variables in a six-dimensional configurational space: three Euler angles $(\delta, \beta, \gamma)$ which characterize the system as a whole and the relative variables i.e. the hyperradius $(R)$, the hyperangle $(\alpha)$ and the angle between the vector radii of electrons

$$
\begin{aligned}
& R=\sqrt{{\overrightarrow{r_{1}}}^{2}+{\overrightarrow{r_{2}}}^{2}}, \quad \alpha=2 \operatorname{arctg} \frac{r_{1}}{r_{2}} \\
& \theta=\arccos \frac{\overrightarrow{r_{1}} \overrightarrow{r_{2}}}{r_{1} r_{2}}
\end{aligned}
$$

Equation (1) assumes the following form in these variables

$$
[T+V(R, \alpha, \theta)-E] \Psi(R, \alpha, \theta, \delta, \beta, \gamma)=0
$$

where $T, V$ are the kinetic and potential energy operators, respectively, which have the form [32] 


$$
\begin{aligned}
& T=\frac{1}{2}\left\{\frac{1}{R^{5}} \frac{\partial}{\partial R}\left(R^{5} \frac{\partial}{\partial R}\right)+\frac{4}{R^{2} \sin ^{2} \alpha}\left[\frac{\partial}{\partial \alpha}\left(\sin ^{2} \alpha \frac{\partial}{\partial \alpha}\right)+\frac{1}{\sin \theta} \frac{\partial}{\partial \theta}\left(\sin \theta \frac{\partial}{\partial \theta}\right)\right]\right\} \\
& +\frac{1}{R^{2} \sin ^{2} \alpha}\left\{\frac{\vec{J}^{2}+\cos \theta\left(J_{x}^{2}-J_{y}^{2}\right)}{\sin ^{2} \theta}-\frac{1-\cos ^{2} \theta}{2 \sin ^{2} \theta} J_{z}^{2}+\frac{\cos \alpha}{\sin \theta}\left\{J_{x}, J_{y}\right\}+i \cos \alpha J_{z}\left(\frac{\partial}{\partial \theta}+\operatorname{ctg} \theta\right)\right\} \\
& V(R, \alpha, \theta)=-\frac{1}{R}\left(\frac{Z}{\sin \frac{\alpha}{2}}+\frac{Z}{\cos \frac{\alpha}{2}}-\frac{1}{\sqrt{1-\sin \alpha \cos \theta}}\right)
\end{aligned}
$$

$J_{x}, J_{y}, J_{z}$ are the projections of the angular momentum operator, acting on Euler angles $(\delta, \beta, \gamma)$. These operators have the form [33]

$$
\begin{aligned}
& \vec{J}^{2}=-\left[\frac{\partial^{2}}{\partial \beta^{2}}+\operatorname{ctg} \beta \frac{\partial}{\partial \beta}+\frac{1}{\sin ^{2} \beta}\left(\frac{\partial^{2}}{\partial \delta^{2}}-2 \cos \beta \frac{\partial^{2}}{\partial \delta \partial \gamma}+\frac{\partial^{2}}{\partial \gamma^{2}}\right)\right], \\
& J_{z}=\frac{\partial}{\partial \delta}, J_{x} \pm J_{y}=\frac{1}{\sqrt{2}} \exp (\mp i \gamma)\left[ \pm \operatorname{ctg} \beta \frac{\partial}{\partial \gamma} \mp i \frac{\partial}{\partial \beta} \mp \frac{1}{\sin \beta} \frac{\partial}{\partial \delta}\right] .
\end{aligned}
$$

Let us express the solution of equation (3) in the form of a series in Wigner functions $D_{M M^{\prime}}^{J}(\delta, \beta, \gamma)[33]$

$$
\begin{aligned}
& \Psi(R, \alpha, \theta, \delta, \beta, \gamma) \\
& =\sum_{J, M, M^{\prime}} f_{M M^{\prime}}^{J}(R, \alpha, \theta) D_{M M^{\prime}}^{J}(\delta, \beta, \gamma),
\end{aligned}
$$

where $f_{M M^{\prime}}^{J}(R, \alpha, \theta)$ are the unknown coefficients. These coefficients obey the system of second order partial differential equation of $2 \mathrm{j}+1$-dimension. For $S$-states this system is reduced to a single equation

$$
\begin{aligned}
& {\left[\frac{1}{R^{5}} \frac{\partial}{\partial R}\left(R^{5} \frac{\partial}{\partial R}\right)+\frac{4}{R^{2}} \Lambda^{2}-2 V(R, \alpha, \theta)+2 E\right]} \\
& \times f(R, \alpha, \theta)=0,
\end{aligned}
$$

where

$$
\Lambda^{2}=L_{\alpha}+\frac{1}{\sin ^{2} \alpha} L_{\theta}
$$

is the square of generalized angular momentum operator and

$$
\begin{aligned}
& L_{\alpha}=\frac{1}{\sin ^{2} \alpha} \frac{\partial}{\partial \alpha}\left(\sin ^{2} \alpha \frac{\partial}{\partial \alpha}\right), \\
& L_{\theta}=\frac{1}{\sin \theta} \frac{\partial}{\partial \theta}\left(\sin \theta \frac{\partial}{\partial \theta}\right) .
\end{aligned}
$$

The operator $\Lambda^{2}$ has the eigenvalues $(n+m+1)^{2}$ and the eigenfunctions [34]

$$
\begin{aligned}
& \Phi_{n m}(\alpha, \theta)=N_{n m}(\sin \alpha)^{m} \\
& C_{n}^{m+1}(\cos \alpha) P_{m}(\cos \theta),
\end{aligned}
$$

$C_{n}^{m+1}(\cos \alpha)$ and $P_{m}(\cos \theta)$ are the Gegenbauer and Legandre's polynomials respectively, $\mathrm{N}$ is the normalizing constant, which has the form of

$$
N_{n m}=\frac{\pi \Gamma(2 m+n+1)}{2^{2 m} n !\left(n+m+\frac{1}{2}\right)\left[\Gamma\left(m+\frac{1}{2}\right)\right]^{2}} .
$$

Eigenfunctions (6) are widely used as basic functions in the case of short-range potentials [7]. In atomic physics the interaction potential has a Coulombic form and the expansion series in these basic functions (6) converges very slowly. Therefore in this case it is more advantageous to use other basic functions, namely those which are the eigenfunctions of a 2-dimensional operator on sphere [3]

$$
\begin{aligned}
& {\left[\Lambda^{2}-\frac{1}{2} R^{2} V(R, \alpha, \theta)\right] \chi_{\mu}(R, \alpha, \theta)} \\
& =-R^{2} U_{\mu}(R) \chi_{\mu}(R, \alpha, \theta)
\end{aligned}
$$

where $U_{\mu}(R)$ are the eigenvalues (adiabatic potentials). From (7) it is clear, that both eigenfunctions, called channel-functions and the adiabatic potentials depend on the hyperradius $R$. 


\section{A. A numerical calculation of the adiabatic} potentials and the angular part of wave functions

It is impossible to obtain the exact solution of (7) in the general case. For the approximate solution of equation (7) we shall use the iterative procedure, which is described e.g. in [30, 31]. Let us note that the separation of the variables and its partial solutions are expressed by function (6). Let us suggest that for all the values of $R$ the solution of (7) has a separable form

$$
\chi_{n m}(R, \alpha, \theta)=g_{n}(R, \alpha) f_{m}(R, \theta),
$$

where $g_{n}(R, \alpha)$ and $f_{m},(R, \theta)$ are unknown functions which depend parametrically on $R$ and which obey the following conditions

$$
\begin{aligned}
& \chi_{n m}(0, \alpha, \theta)=g_{n}(0, \alpha) f_{m}(0, \theta) \\
& =\Phi_{n m}(\alpha, \theta)
\end{aligned}
$$

in the region $D(0 \leq \alpha, \theta \leq \pi)$, while on the verge of region $\mathrm{D}$ one has

$$
\begin{aligned}
& g_{n}(R, 0)=0, g_{n}(R, \pi)=0 \\
& \frac{\partial}{\partial \theta} f_{m}(R, 0)=0 \\
& \frac{\partial}{\partial \theta} f_{m}(R, \pi)=0
\end{aligned}
$$

according to (6) and (9). For solving equation (7) with the boundary conditions (10) we take as the first step of iteration $f_{m}^{(0)}(R, \theta)=P_{m}(\cos \theta)$. Then for defining $g_{n}^{(1)}(R, \alpha) \chi_{n m}^{(i+j)}(R, \alpha, \theta)=g_{n}^{(i)}(R, \alpha) f_{m}^{(j)}(R, \theta)$ from (7) we obtain the equation

$$
\begin{aligned}
& \left\{L_{\theta}+\frac{1}{\sin ^{2} \alpha}\left(f_{m}^{(0)}, L_{\theta} f_{m}^{(0)}\right)+\left(f_{m}^{(0)}, \tilde{V} f_{m}^{(0)}\right)\right. \\
& \left.+\left(f_{m}^{(0)}, f_{m}^{(0)}\right) \Lambda_{n m}^{(1)}\right\} g_{n}^{(1)}(R, \alpha)=0,
\end{aligned}
$$

where

$$
\Lambda_{n m}^{(1)}=R^{2} U_{n m}^{(1)}(R),(\varphi, A \chi)=\int_{0}^{\pi} \varphi(\theta) A(\theta) \chi(\theta) \sin \theta d \theta
$$

is a matrix element of the A operator, $\hat{V}$ is the potential energy operator, multiplied by $R^{2} / 2$. Solving problem (11) with the boundary conditions (10) we obtain eigenfunctions $g_{n}^{(1)}(R, \alpha)$ and eigen-values $\Lambda_{n m}^{(1)}$. On the second step we put $\chi_{n m}^{(2)}(R, \alpha, \theta)=g_{n}^{(1)}(R, \alpha) f_{m}^{(1)}(R, \theta)$. For defining $f_{m}^{(1)}(R, \theta)$ the following equation is to be used

$$
\begin{aligned}
& \left\{\left(g_{n}^{(1)}, \frac{1}{\sin ^{2} \alpha} g_{n}^{(1)}\right) L_{\theta}\right. \\
& +\left(g_{n}^{(1)}, L_{\alpha} g_{n}^{(1)}\right)+\left(g_{n}^{(1)}, \tilde{V} g_{n}^{(1)}\right) \\
& \left.+\left(g_{n}^{(1)}, L_{\alpha} g_{n}^{(1)}\right) \Lambda_{n m}^{(1)}\right\} f_{m}^{(j)}(R, \theta)=0 .
\end{aligned}
$$

The integration over $\alpha$ in the matrix elements in (12) is carried out with the weight $\sin ^{2} \alpha$. Since equation (7) is invariant under the transformation $\alpha^{\prime}=\pi-\alpha$ the integration over $\alpha$ is to be carried out in the interval $[0, \pi / 2]$, while for singlet states $g_{n}(R, \alpha)$ is even in respect to point $\alpha=\pi / 2$ and is odd for triplet states. Solving eq. (12) with taking into account eq. (10) we obtain $f_{m}^{(1)}(R, \theta)$ and $\Lambda_{n m}^{(2)}$. Let us continue this process until the condition $\left|\Lambda_{n m}^{(k)}-\Lambda_{n m}^{(k-1)}\right|<\varepsilon$, is satisfied, $\varepsilon$ being the given precision defining the adiabatic potentials.

The described process was realized numerically for six lowest adiabatic potentials, describing the ${ }^{1} S$-states of the $\mathrm{He}$ atom and a negative hydrogen ion. While solving eq. (7) the sweep method with conditions of conjugation $[30,31]$ was used. It allowed us to determine the adiabatic potentials with the precision of up to $10^{-4}$ a.u. To reach this precision for every fixed value of hyperradius it was necessary to carry out from four to six iterations. Taking into account the interaction potential between the electrons was carried out by way of using the following multipole expansion [33]

$$
\frac{1}{\sqrt{1-\sin \alpha \cos \theta}}=\sum\left\{\begin{array}{l}
\frac{1}{\cos (\alpha / 2)} \operatorname{tg}^{n}(\alpha / 2) P_{n}(\cos \theta), 0 \leq \alpha \leq \pi / 2 \\
\frac{1}{\sin (\alpha / 2)} \operatorname{ctg}^{n}(\alpha / 2) P_{n}(\cos \theta), \pi / 2 \leq \alpha \leq \pi
\end{array}\right.
$$

Obtaining numerical values of lower adiabatic potentials with a given precision demands the inclusion into expansion (13) of up to ten terms. The convergence of expansion (13) is characterized by the data shown in table 1. 


\begin{tabular}{ccccccc}
$R$ & \multicolumn{2}{c}{$-R^{2} U_{00}(R)$} & & $-R^{2} U_{11}(R)$ & & $-R^{2} U_{22}(R)$ \\
& $\mathrm{n}=2$, & $\mathrm{n}=3$, & $\mathrm{n}=4$ & $\mathrm{n}=2, \mathrm{n}=3, \quad \mathrm{n}=4, \quad \mathrm{n}=5$ & $\mathrm{n}=3, \quad \mathrm{n}=4$ \\
0.1 & $0.8917 ;$ & $0.8916 ;$ & 0.8916 & $3.9061 ; 3.9197 ; 3.9197 ; 3.9196$ & $8.8339 ; 8.8341$ \\
0.3 & $0.6688 ;$ & $0.6686 ;$ & 0.6686 & $3.7198 ; 3.7605 ; 3.7597 ; 3.7595$ & $8.4674 ; 8.4674$ \\
0.5 & $0.4420 ;$ & $0.4417 ;$ & 0.4417 & $3.5437 ; 3.6715 ; 3.5990 ; 3.5988$ & $8.0981 ; 8.0979$ \\
1.0 & $-0.1421 ;-0.1428 ;-0.1431$ & $3.0728 ; 3.2034 ; 3.1927 ; 3.1926$ & $7.1618 ; 7.1616$ \\
1.5 & $-0.7535 ;-0.7548 ;-0.7548$ & $2.6138 ; 2.8030 ; 2.7826 ; 2.7801$ & $6.2090 ; 6.2090$ \\
2.0 & $-1.3964 ;-1.3978 ;-1.3978$ & $2.1560 ; 2.3985 ; 2.3637 ; 2.3602$ & $5.2421 ; 5.2412$
\end{tabular}

Table 1. Contribution of multipoles in lower adiabatic potentials.
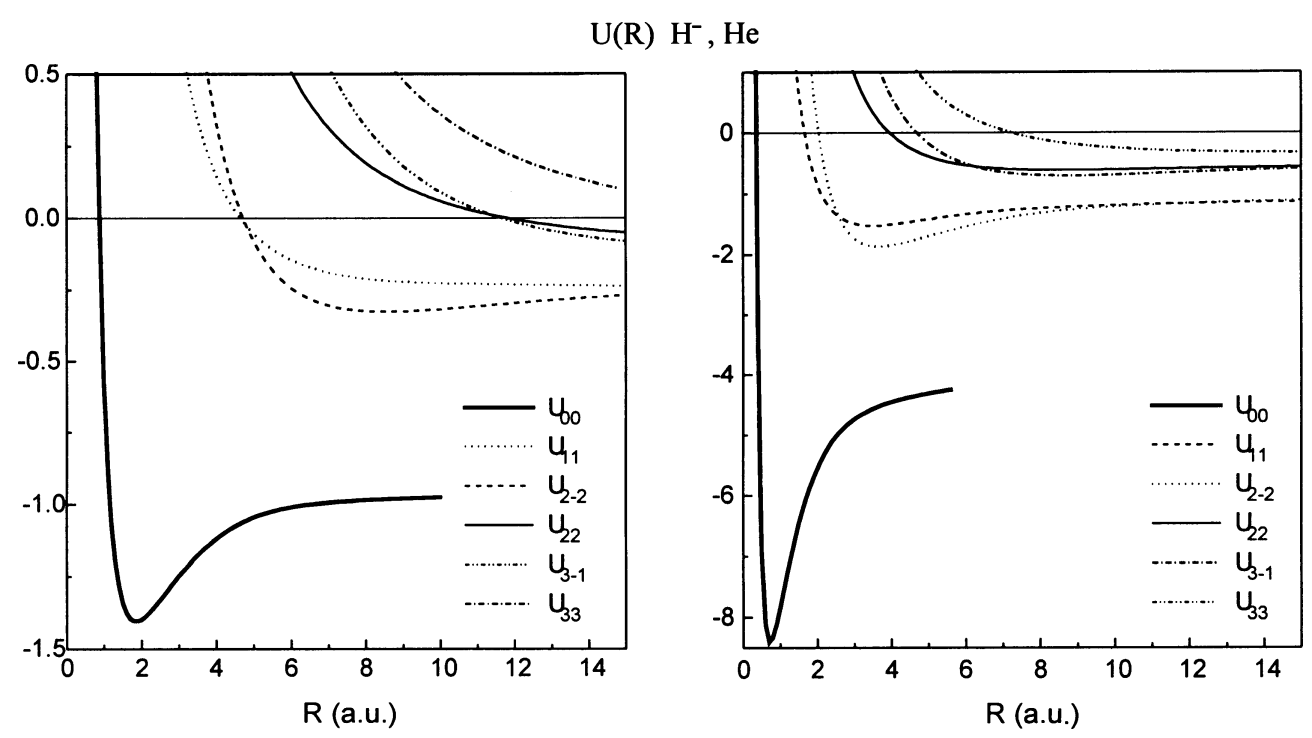

Fig. 1. Lower adiabatic potentials for $\mathrm{He}$ and $\mathrm{H}^{-}$.

As it is seen from the table for the series $m s^{2}$ it is sufficient to account three terms in expansion (13), for the other series the number of terms in the expansion depends on the number of knots of wave functions in respect to the variable $\theta$.

In the standard approach [3-6, 21-23] the evaluation of channel function is reduced to the system of homogeneous algebraic equations or Sturm-Liouville-type problem for the system of second order differential equations. The accuracy of the account of the angular correlations depends on the dimension of the system of these algebraic or differential equations and on the sort of basic functions used in the expansion of channel functions. The obtained lowest adiabatic potentials for $\mathrm{He}$ and $\mathrm{H}^{-}$are shown in fig. 1, while the wave functions, corresponding to the lowest series for small and medium hyperradius values are shown in fig. 2. As it was shown in [35] the states of helium-like atoms are conveniently characterized by two numbers $\sigma=n+l$ and $\rho=l-n$. One of these numbers is connected with the generalized angular momentum $(\Lambda=\sigma+1)$ while the second is indicating the number of states in a multiplet. These numbers are char- acterizing the adiabatic potential unambiguously. As it is seen from fig. 1 some potentials are describing the attraction in some region of hyperradius which secures the existence of bound states, while other potentials show repulsion which shows itself only in scattering and ionisation.

The wave functions or more precisely their square of moduli is proportional to the electric probability density at fixed hyperradius. As follows from fig. 2 this quantity depends very strongly on hyperradius. At small values of $R$ it is close to "free" (4), while at large values of $R$ the density depends on $R$ very strongly. This statement is visualized in more details in fig. 3 . The analysis of this fig. shows that the correlation in respect of $\alpha$ is more essential in comparison with the dependence on $\theta$. This fact indicates that the quantum number $l$ can be used with a good precision for characterizing the states of systems, especially for the lower one- and two-electron excited states.

The obtained wave functions allow to define the nonadiabatic potentials which provide the coupling between the channels in the system of radial equations [29, 34]. 

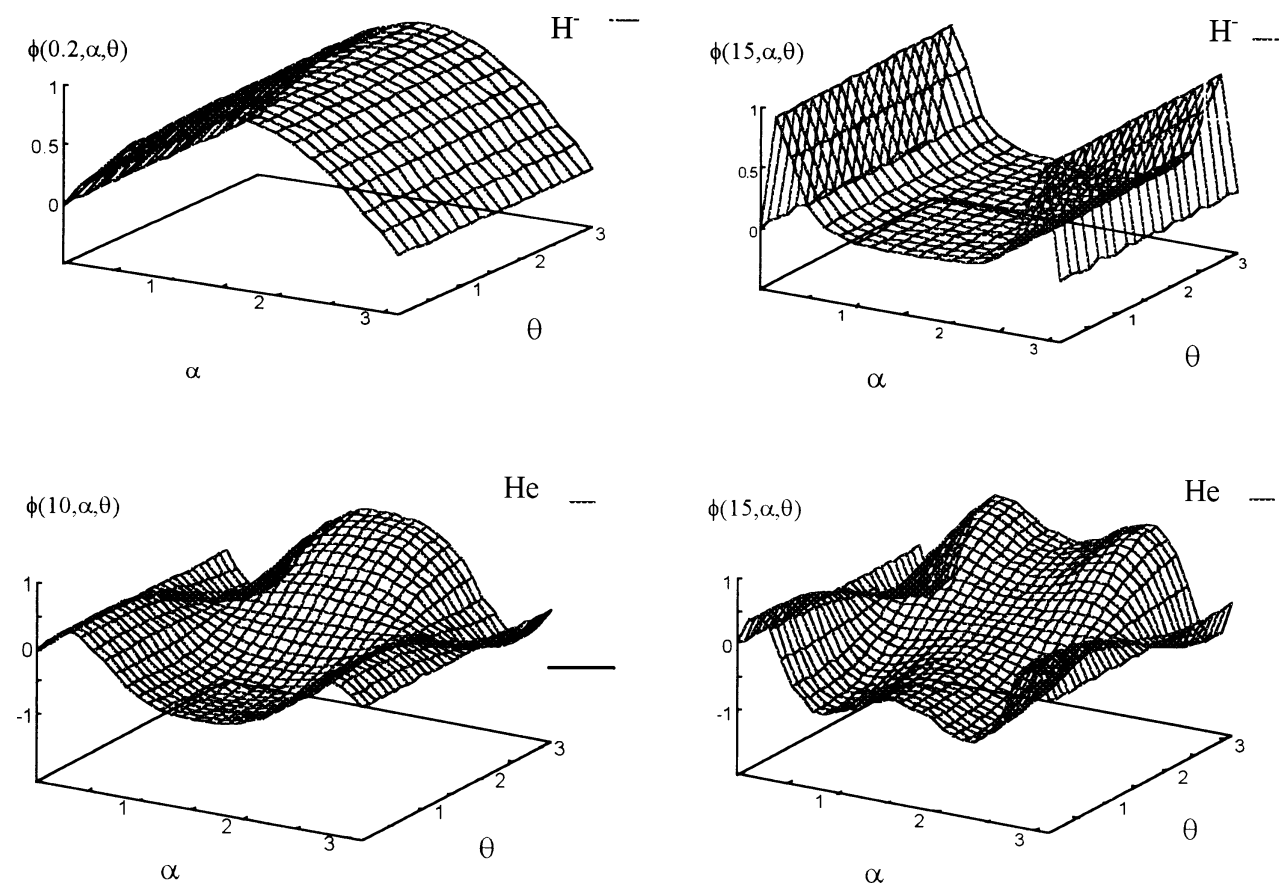

Fig. 2. Angular parts of wave functions of the ground state $\mathrm{H}^{-}$and of the autoionising $U_{3-1}$ term of He.
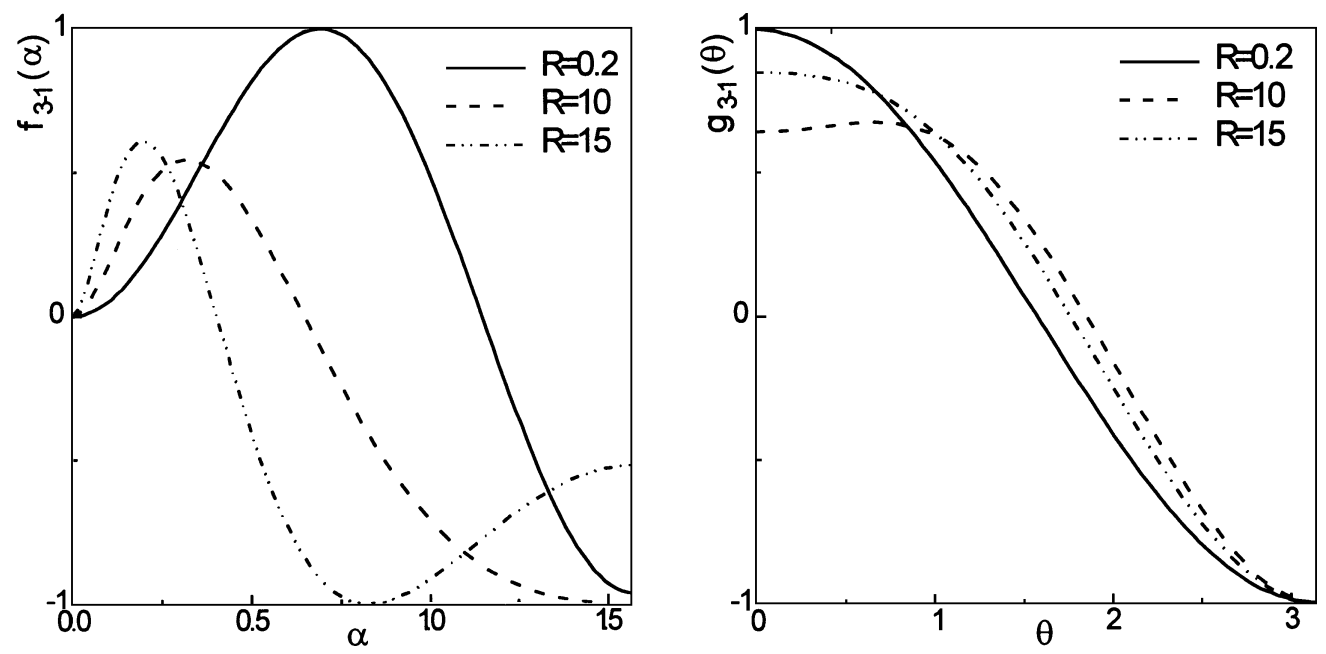

Fig. 3. The dependence of wave functions $f_{3-1}(\alpha)$ and $g_{3-1}(\theta)$ for the helium atom.

The existence of the crossing of the potentials $U_{2-2}$ and $U_{11}$ indicates the mixing of the configurations $s^{2}$ and $d^{2}$ at small values of hyperradius and configurations $s^{2}$ and $p^{2}$ at the asymptotical values of $R$. In the vicinity of the crossing points the transitions between these configurations are possible. It is interesting to note that similar transitions were not observed in a polyspheric system. However in the case of $p e e^{+}$in [26] a similar crossing was obtained for adiabatic potentials in the vicinity of $R \simeq 9$ a.u. In our case, as it is shown in fig. 1 two crossings are obtained both for $\mathrm{H}^{-}$and for He. Similar crossings of terms in collisions of heavy particles [36] result in the oscillations of cross-sections. It would be of certain interest to check this idea in the case of electron-atom or electron-ion scattering.

In conclusion we can say that using two-dimensional adiabatic basis allows one to describe both angular and radial correlations of helium-like systems, to limelight the region of $\mathrm{CI}$ in which nonadiabatic correlations play an important role. 
[1] I. O. Vakarchuk, I. R. Yukhnovsky, Teor. Mat. Fiz. 40, 100 (1979).

[2] I. O. Vakarchuk, O. L. Gonopolsky, I. R. Yukhnovsky, Teor. Mat. Fiz. 41, 77 (1979).

[3] J. H. Machek, J. Phys. B 1, 831 (1968).

[4] U. Fano, Rep. Prog. Phys. 46, 97 (1983).

[5] C. D. Lin, Adv. At. Mol. Phys. 22, 77 (1986).

[6] U. Fano, A. R. P. Rau, Atomic collisions and Spectra (Academic Press, INC, 1986).

[7] R. I. Jibuti, K. V. Shitikova, Method of hyperspherical functions in atomic and nuclear physics (Energoatomizdat, Moscow, 1993).

[8] D. R. Hartree, The Calculation of Atomic Structures (J, Wiley, New-York, 1980).

[9] C. D. Fisher, The Hartree-Fock Method for Atoms (J: Wiley, New-York, 1977).

[10] L. Lipsky, A. Russek, Phys. Rev. 142, 59 (1966).

[11] P. G. Burke, D. D. Mcvicar, Proc. Phys. Soc. 86, 989 (1965).

[12] K. Smith, The Calculation of Atomic Collision Processes (J. Wiiley, New-York, 1971).

[13] B.P. Jigunov, B. N. Zakharev, Strong coupling method in quantum scattering theory (Energoatomizdat, Moscow, 1974).

[14] E. Kamke Differentialgleichungen lösungmethoden und lösungen (Leipzig, 1959).

[15] J. H. Bartlett, Phys. Rev. 51, 661 (1937).

[16] V. A. Fock, Izv. Akad. Nauk SSSR 18, 161 (1954).

[17] A. Kono, S. Hattori, Phys. Rev. A 29, 2981 (1984).

[18] F. S. Levin, J. Schertzer, Phys. Rev. A 32, 3285 (1985).

[19] E. A. Hylleraas, J. Midtal, Phys. Rev. 103, 829 (1956).
[20] J. M. Feagin , J. Macek, A. F. Starce, Phys. Rev. A 32, 337 (1985).

[21] M. I. Haysak, V. I. Lengyel, V. Yu. Pojda, Ukr. Fiz. Zh. 33, 664 (1985).

[22] A. G. Abraskevich, M. I. Haysak, V. I. Lengyel, V. Yu. Pojda, I. V. Puzinin, Phys. Lett. A 133, 140 (1988).

[23] A. G. Abraskevich , D. G. Abraskevich, M. I. Haysak, V. I. Lengyel, V. I. Puzinin, S. I. Vinitski, Phys. Lett. A 152, 467 (1991).

[24] H. Klar, M. Klar, J. Phys. B 13, 1052 (1980).

[25] C. D. Lin, Phys. Rev. Lett. 35, 1150 (1975).

[26] E. Pelikan, H. Klar, J. Phys. A 310, 153 (1983).

[27] C. H. Green, Phys. Rev. A 23, 661 (1981).

[28] D. R. Herrick, Phys. Rev. A 12, 413 (1975).

[29] S. I. Nikitin, V. N. Ostrovsky, J. Phys. B 18, 4349 (1985).

[30] M. I. Dovhanich, I. Yu. Korol, Prikladna Mekh. 14, 80 (1978).

[31] M. I. Dovhanich, Prikladna Mekh. 23, 75 (1987).

[32] B. R. Johnson, J. Chem. Phys. 79, 1916 (1983).

[33] D. A. Varshalovich, A. N. Moskalev, V. K. Khersonsky, Quantum theory of angular momentum (Nauka, Leningrad, 1979).

[34] M. Haysak, I. Haysak, M. Dovhanich, Proceedings of the 3rd Triangle Seminar on Atomic Collision Processes (Uzhgorod, 18, 1993).

[35] M. I. Haysak, M. M. Dovhanich . Abst. of paper on 5th Intern. Workshop Autoionization Phenomena in Atoms, (Dubna, Moscow Univ. Press, 61, 1995).

[36] B. A. Ankudinov, S. V. Bobashev, A. V. Perel, Zh. Eksp. Teor. Fiz. 60, 906 (1971).

\title{
ДВОВИМІРНИЙ БАЗИС ДЛЯ ДОСЛІДЖЕННЯ КУТОВИХ КОРЕЛЯЩЙ В ГЕЛІЕПОДІБНИХ СИСТЕМАХ
}

\author{
М. І. Гайсак ${ }^{\dagger}$, М. М. Довганич ${ }^{\dagger}$ В. І. Лендьел ${ }^{\dagger \dagger}$, В. В. Онисько ${ }^{\dagger \dagger}$ \\ ${ }^{\dagger}$ Інститут електронної фізики НАН Украйни, 294016 м. Уэсгород, вул. Університетсъка, 21 \\ ${ }^{\dagger \dagger}$ Ужггродсъкий державний універсисет, 294000 м. Ужггрод, вул. Волошина, 32
}

\begin{abstract}
На шляху використання методу гіперсферичних координат запропоновано використання двовимірного базису для дослідження внеску кутових кореляцій у спектроскопічні характеристики тричастинкових систем. Розроблено алгоритм та складено комплекс програм, які дають можливість розв'язувати задачу на власні значення для лінійних диференціяльних рівнянь у частинних похідних другого порядку від двох незалежних змінних із змінними коефіцієнтами, які можуть мати сингулярність на границі області інтегрування. На основі розв'язування крайової задачі двох незалежних змінних в адіябатичному наближенні проведено розрахунки для шести нижчих адіябатичних потенціялів та кутових частин хвильових функцій, що описують одночастинкові та двочастинкові (автойонізаційні) збудження $S$-станів двоелектронних систем Не та $\mathrm{H}^{-}$.

Виявлено дійсні точки перетину адіябатичних потенціялів, які характеризують області неадіябатичних переходів між серіями автойонізаційних станів. Запропонована класифікація адіябатичних потенціялів тричастинкових систем на основі вузлових ліній кутової частини хвильової функції. Досліджено внесок вищих монополів в адіябатичні потенціяли та каналові функції. Показано, що включення чотирьох доданків розкладу потенціялу міжелектронної взаємодії дозволяє одержати адіябатичні потенціяли з точністю $10^{-4}$ а.о.. На відміну від стандартного підходу, використання двовимірного базису дає можливість більш повно описати кореляційний рух електронів уже в адіябатичному наближенні.
\end{abstract}

